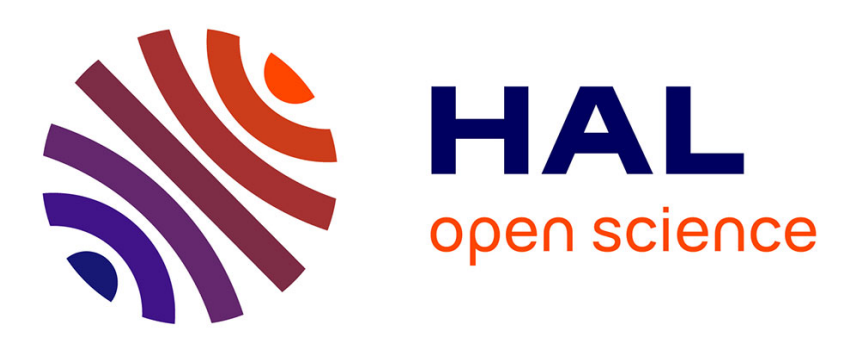

\title{
Distinguishing orthorexic behaviors from eating disordered and obsessive--compulsive behaviors: a typological study
}

Ecem Yakin, Patrick Raynal, Henri Chabrol

\section{- To cite this version:}

Ecem Yakin, Patrick Raynal, Henri Chabrol. Distinguishing orthorexic behaviors from eating disordered and obsessive-compulsive behaviors: a typological study. Eating and Weight Disorders Studies on Anorexia, Bulimia and Obesity, In press, 26, pp.2011-2019. 10.1007/s40519-020-01037-9 . hal-03197414

HAL Id: hal-03197414

https://hal-univ-tlse2.archives-ouvertes.fr/hal-03197414

Submitted on 13 Apr 2021

HAL is a multi-disciplinary open access archive for the deposit and dissemination of scientific research documents, whether they are published or not. The documents may come from teaching and research institutions in France or abroad, or from public or private research centers.
L'archive ouverte pluridisciplinaire HAL, est destinée au dépôt et à la diffusion de documents scientifiques de niveau recherche, publiés ou non, émanant des établissements d'enseignement et de recherche français ou étrangers, des laboratoires publics ou privés. 
Distinguishing orthorexic behaviors from eating disordered and obsessive-compulsive behaviors: A typological study

Ecem Yakın, Patrick Raynal, and Henri Chabrol

Centre d'Etudes et de Recherches en Psychopathologie et Psychologie de la Santé, Université de Toulouse, UT2J, France

Corresponding author: Ecem Yakın

Laboratoire CERPPS, Université de Toulouse-Jean Jaurès, 5 allées Antonio Machado, 31058

Toulouse, Phone number: +33 06675646 91, E-mail: ecem.yakin@univ-tlse2.fr

Acknowledgments: We would like to thank Pr. David H. Gleaves for giving us the permission to translate the Eating Habits Questionnaire. 


\begin{abstract}
Purpose: This study represents a first attempt to explore the typology of young adults from a large non-clinical sample based on orthorexic (ON), eating disordered (ED) and obsessive-compulsive behaviors (OCD). Methods: 921 individuals (Mage $=20.72, \mathrm{SD}=2.63), 84.6 \%$ women $(\mathrm{n}=780)$ and $15.3 \%$ men $(\mathrm{n}=141)$, completed a set of questionnaires assessing ON, ED, OCD behaviors and body image attitudes. Results: Cluster analysis based on ON, ED and OCD behaviors yielded four clearly distinct groups: a "Low" group that was below the sample mean for all behaviors, an "Orthorexic behaviors" group, an "Eating disordered behaviors" and an "Obsessive-compulsive behaviors" group with, respectively, mean scores on ON, ED and OCD behaviors that all were all above the sample means. Using ANOVA, these groups were compared regarding body image attitudes, self-reported BMI, age and educational level. Results show that all clusters differed from each other on virtually all variables. And compared with all other clusters, the "Orthorexic behaviors" cluster displayed greater scores in health and fitness-related aspects of body image. It also differed from the "Eating disordered behaviors" cluster, by its higher scores in appearance evaluation, body areas satisfaction and lower scores in self-classified weight. Conclusion: This study demonstrates the existence of a distinct group of individuals with orthorexic behaviors and its positive body image attitudes and offer significant support for the possibility of ON being a distinct condition from ED and OCD.
\end{abstract}

Keywords: Orthorexia nervosa, Eating disorders, Obsessive-compulsive disorders, Body image Level of evidence: Level V, descriptive study. 


\section{Introduction}

Orthorexia Nervosa $(\mathrm{ON})$ is proposed to be an eating behavior characterized by excessive preoccupation with healthy nutrition leading to qualitative and quantitative dietary restrictions [1]. Some studies reported that orthorexic behaviors could result in reduced psychological well-being [2], severe malnutrition [3] or medical complications [4].

Existing data indicates a prevalence of $\mathrm{ON}$ in the range of less than $1 \%$ [5] to $57.6 \%$ [6] in the general population. There are also inconsistent findings on correlations of ON with age, sex, educational level and body mass index (BMI) [6-10]. These divergent findings, including the variability of ON prevalence can be explained by sociocultural differences between countries in which studies are conducted [11], characteristics of selected populations and the use of different measurement tools [12]. In fact, some of the commonly used measures of ON were criticized for having poor psychometric properties [13] and for not being able to distinguish between healthy and pathological eating [14].

In addition, although $\mathrm{ON}$ is gaining increasing scientific attention, it is not recognized as a separate mental disorder and it is not classified in The Diagnostic and Statistical Manual of Mental Disorders-Fifth Edition (DSM-5) [15] or International Classification of Diseases-11th Edition (ICD-11) [16]. This may be explained by the current state of research characterized by controversial findings, as mentioned in the above paragraph, but also by the still ongoing debate about the conceptualization of $\mathrm{ON}$ and its categorization among other mental disorders [2].

Indeed, it is well known that eating disorders (ED), especially anorexia nervosa (AN) and bulimia nervosa $(\mathrm{BN})$, are promoted by weight- and shape-related concerns $[17,18]$. However, it was suggested [19] that ON and ED could differ from each other regarding body image and that, in contrast to AN and BN, ON was not characterized by negative body image attitudes (e.g., weight- and shape-related concerns) or intentional weight loss. This suggestion was later supported by findings on the lack of significant correlations between orthorexic behaviors and body dissatisfaction [20] or weight loss attempts [21]. Furthermore, in a review of literature about ON [1] it suggested that sufficient evidence existed to pursue that $\mathrm{ON}$ is a condition distinct from currently classified EDs and that it deserves its own diagnostic criteria. 
Nevertheless, other studies yielded similarities between ON and ED, suggesting that ON could be a variant of existing EDs. In fact, some studies reported that the shared features between ON and ED included negative body image attitudes (e.g., high fitness orientation; investment in being physically fit; high appearance orientation; greater investment in one's physical appearance, overvaluation of body weight, concern about physical appearance, overweight preoccupation and body dissatisfaction $[22,23]$. A recent study conducted with a sample of young females revealed significant associations between $\mathrm{ON}$ and several psychopathological aspects of other eating disorders, and suggested body dissatisfaction as an important component of ON [24]. In a longitudinal study [25] the rate of ON was found to be increased ( 28 to $58 \%$ ) among patients with AN and BN, 3 years after receiving a treatment for EDs. Another study [26] suggested that female AN patients with pronounced $\mathrm{ON}$ felt more autonomous and competent while learning to change their problematic eating patterns, compared to those with low levels of ON. It was thus suggested that ON might serve as a coping strategy in individuals with AN [26].

Other authors proposed that ON could be considered as a form of obsessive-compulsive disorder (OCD) [27]. The main reasons advanced for considering ON as a form of OCD are the ruminations about food quality, the concerns over contamination and impurity, and the rituals around food preparation that individuals with orthorexic behaviors are thought to manifest [28]. However, there is little and contradictory empirical evidence for this presumed connection between ON and OCD [2].

Contradictory findings mentioned above indicate that the question of whether $\mathrm{ON}$ is a variant of existing ED or OCD, or a separate disorder, or not quite a disorder has not been resolved. There is a growing body of research about $\mathrm{ON}$, its similarities with and differences from other pathologies. Yet, to our knowledge, there is no typological study addressing ON. However, typological approach and the use of cluster analysis are preferred for classification of diseases as they allow to detect and differentiate subgroups of individuals with similar characteristics, clinical signs and symptoms [29]. Thus, its use may be helpful to better capture the behavioral patterns of people with ON. Further, there is significant evidence that $\mathrm{ON}, \mathrm{ED}$ and $\mathrm{OCD}$ behaviors are experienced by non-clinical 
populations [9, 30, 31]. And, studying non-clinical populations allows to investigate the occurrence of several symptoms without complications of an established illness [32].

In this study, the Eating Habits Questionnaire assessing orthorexic behaviors was translated into French language. A confirmatory factor analysis was conducted on the French version of this scale to test the original factorial structure. Then, a cluster analysis was used to explore the typology of individuals from a large non-clinical sample of young adults aged between 18 and 30 years old (frequently applied age range in previous studies [33]) based on orthorexic, eating disordered and obsessive-compulsive behaviors. We also compared clusters based on body image attitudes and some of the key socio-demographic variables such as sex, age, educational level and BMI.

\section{Method}

\subsection{Participants and procedure}

The data were collected through an online survey that was distributed to students from different French universities. The link was shared on Facebook, in groups specifically dedicated to students. An online questionnaire was used to provide information regarding the aims of the study and the anonymity of the collected responses. All participants agreed to give their free and informed consent prior to completing the study. Individuals who did not give informed consent and those who were $<18$ or $>30$ years of age were excluded from the study. To avoid random responding, a simple question was asked several times in different forms (i.e., "what is your age -in years-?" and "what is your birth year?"). Participants who provided different answers to these questions were excluded from the study. The IP addresses were not collected in order to assure the anonymity of the collected responses. Instead, usernames (first letters of name and last name and last two numbers of the year of birth) and time signatures (time taken to complete the questionnaire by each participant) were used to detect and exclude bots and multiple entries from the study. Among 921 participants, $84.6 \%$ were women $(n=780), 15.3 \%$ were men $(n=141)$. Their mean age was $20.72(\mathrm{SD}=2.63)$ and their average BMI was $21.96(S D=3.96)$. The study followed the World Medical Association Declaration of Helsinki and the study protocol was approved by the local ethics committee (Comité d'Éthique de la Recherche of Toulouse University). 


\subsection{Measures}

First, participants completed a set of demographic questions (age, sex, educational level) and then the following questionnaires.

\subsubsection{Orthorexic behaviors. The Eating Habits Questionnaire (EHQ) [34] was used to measure} orthorexic behaviors. This 21-item scale has a 3-factor structure with Knowledge, Problems and Feelings subscales with Cronbach's $\alpha=.82, .90$ and .86 , respectively [34]. The first subscale includes 5 items on knowledge about healthy eating (e.g., "I prepare food in the most healthful way"), the second includes 12 items on problems associated with healthy eating (e.g., "My diet affects the type of employment I would take"), and the third subscale includes 4 items on positive feelings about healthy eating (e.g., "I feel great when I eat healthy"). Items are rated on a 4-point scale from $1=$ "false, not at all true" to 4 = "very true". Permission was obtained from Pr. David H. Gleaves to translate and validate EHQ in French language. The translation and back-translation for this scale were conducted by authors, who were fluent in both languages (HC, PR, EY). The main goal of this translation process was to keep the French version as similar as possible to the original version of the scale. Thus, the original version was carefully analyzed in order to avoid any mistranslation or eventual item bias. This allowed a better understanding of how these items might be translated correctly into French language. The cultural differences were also carefully taken into account during this step, as one word or an expression could have different significations in English and in French languages. The options of the scale were also carefully translated to have the same range as the original version. The revised French version of the scale was back translated into English by other two authors who were less familiar with the questionnaire, independently. Once the translation and backtranslation processes were finished, the French version of the scale was reviewed multiple times by the others. The final translated version of the questionnaire was administered to a sample of 20 students in order to check for the degree of construct overlap, clarity, understanding or spelling issues. This method also allowed us to confirm that participants were familiar with item formats, rating scales of the EHQ and computer-administered questionnaires. Finally, there were no necessary revisions to be made. 
2.2.2. Eating Disordered Behaviors. Eating disordered behaviors were assessed using the French versions of the Drive for thinness and the Bulimia subscales of the Eating Disorders Inventory-3rd Edition (EDI-3) [35]. The Drive for thinness subscale assesses preoccupation with thinness, dieting and fear of gaining weight (e.g., "I am very afraid of gaining weight"), and the Bulimia subscale evaluates the frequency of disturbed eating behaviors (e.g., "I eat moderately in front of others and stuff myself when they are gone"). The Cronbach's $\alpha$ for French versions of Drive for thinness and Bulimia subscale were .90 and .68 , respectively [35]. Both subscales contain 7 items which are normally scored on a 6-point scale and recoded as $0,0,1,2,3,4$. However, we used a 6-point scale ranging from " 1 = never" to " 6 = always". The data obtained from these scales were standardized for cluster analyses and was secondly used as total mean score for cluster comparison. None of the subscales were used individually. Thus, changing the scoring system to facilitate data analysis in the current study did not damage the reliability of this scale. This scoring system was previously preferred in other studies $[36,37]$

\subsubsection{Obsessive-compulsive behaviors. Obsessive-compulsive behaviors were measured using the}

French version of the Obsessive-Compulsive Inventory Revised (OCI-R) [38]. This scale contains 18 items (e.g., "I check things more often than necessary") scored from $0=$ "Not at all" to $4=$ "Extremely". A high score is an indicator of elevated obsessive-compulsive behaviors. The French version of this scale was found to have satisfactory internal consistency with Cronbach's $\alpha=.86$ [38]. 2.2.4. Self-attitudinal aspects of body image. Self-attitudinal aspects of body image were assessed using the Multidimensional Body-Self Relations Questionnaire (MBSRQ) [39]. The MBSRQ contains 10 subscales assessing satisfaction with and investment in one's appearance, weight, health and fitness. Items are scored on a 5-point scale ranging from $1=$ "Definitely disagree" to 5 = "Definitely agree". We used the French version of 5 subscales related to appearance [40]: the Appearance Evaluation (reflects satisfaction with one's own appearance), the Appearance Orientation (higher scores indicate greater investment in one's appearance), the Body Areas Satisfaction (assesses the general satisfaction with most areas of one's own body), the Overweight Preoccupation (assesses fat anxiety, weight vigilance and dieting) and the Self-Classified Weight subscale (reflects body weight, as perceived by the individual), with Cronbach's $\alpha=.88, .84, .66, .74, .85$, respectively [40]. Other 5 
subscales of the MBSRQ are related to fitness and health: the Health Orientation subscale (reflects investment in healthy lifestyle), the Health Evaluation (assesses feelings of being in good health), the Illness Orientation (assesses reactivity to physical illness), the Fitness Orientation (assesses investment in being physically fit) and the Fitness Evaluation subscale (assesses satisfaction with one's fitness). As no validated French version of these 5 subscales of the MBSRQ exists, translation and back-translation for these scales were conducted by authors, who were fluent in both languages (HC, PR). The Cronbach's alphas and mean inter-item correlations for all scales used in the current study are represented in Table 1.

2.2.5 Body mass index. Participants were requested to provide their height and weight. BMI was calculated as $\mathrm{kg} / \mathrm{m}^{2}$.

\subsection{Statistical analysis}

Statistical analyses were conducted with STATISTICA 10. First, a confirmatory factor analysis was conducted on French version of the EHQ in order to test the factorial structure found in the original study [34]. Cronbach's alpha reliability analyses were conducted to assess the internal consistency of total EHQ score and each subscale. A confirmatory factor analysis was performed on our sample to examine the validity of the initial three-factor structure of the EHQ. A hierarchical cluster analysis was conducted (Ward's method with squared Euclidean distance) on the whole sample. This analysis identified homogeneous groupings of participants based on variable scores converted to z-scores of the EHQ, EDI-3 and OCI-R. We used the dendrogram and the agglomeration schedule to identify the number of clusters. In the second step, K-means clustering was used to assign individuals to one of the identified clusters. Cluster group differences regarding age, BMI, educational level and attitudes towards body image were tested using one-way ANOVA for each variable. Tukey post hoc tests were conducted to determine which clusters were statistically different on each scale.

\section{Results}

\subsection{Assessment of $O N$ with $E H Q$}

A three-factor confirmatory analysis was conducted to test the factorial structure of the EHQ found in the original validation study [34]. As recommended [41] we reported fit indices suitable for large samples: Root Mean Square Error of Approximation (RMSEA), Standardized Root Mean 
Square Residual (SRMR) and Goodness of Fit Index (GFI). The three-factor solution showed a significant RMSEA of .07, a SRMR of .05, and a relatively low but acceptable GFI of .88 . Values closer to 1.00 for the GFI indicate a better model fit [42]. Values at or below .08 for the RMSEA and .06 for the SRMR represent a good model fit [43]. The Cronbach's $\alpha$ for the French version of the EHQ total scale, the Knowledge and Problems subscales showed good internal consistency (Cronbach's $\alpha=.89, .79, .85$, respectively). The Feelings subscale showed acceptable internal consistency (Cronbach's $\alpha=.66$ with $M I C=.42)$.

\subsection{Cluster analysis}

The agglomeration schedule and dendrogram were used to identify the number of clusters. The agglomeration schedule showed a sudden increase in linkage distance when four clusters merged to three clusters (from 91.83 to 128.1). This confirmed that the passage from four to three clusters would have more impact on the heterogeneity of the clusters than previous stages of the analysis. Therefore, the four-cluster solution appeared the most appropriate. A discriminant analysis showed clear differences between clusters (Wilks' lambda $=.092, p<0.0001$ ) with $92 \%$ of cases correctly classified.

Data revealed a first group ( $n=241$ [26\%]; women, $80 \%$ men, 19.9\%) characterized with a mean score on orthorexic behaviors that was above the sample mean by one SD value and with mean scores of ED and OCD behaviors slightly below the sample means (shown in Fig. 1; Table 2). Thus, this group was called "Orthorexic behaviors" cluster. A second group $(n=131$ [14\%]; women, 84.7\%, men, $15.2 \%$ ) with a mean score on OCD behaviors that was above the sample mean by one and a half standard deviation (SD) and mean scores of $\mathrm{ON}$ and ED slightly above the sample means. This group was labeled "Obsessive-compulsive behaviors" cluster. A third group $(n=155$ [16\%]; women, 93.5\%, men, $6.4 \%$ ) had a mean score on ED behaviors above the mean by one and half SD value, while mean scores for ON and OCD behaviors were slightly below the sample means. It was thus termed "Eating disordered behaviors" cluster. A fourth group ( $n=394$ [42\%]; women, 84\%, men, 15.9\%) that was below the sample mean by more than half one SD value for $\mathrm{ED}, \mathrm{ON}$ and $\mathrm{OCD}$ behaviors was named the "Low" cluster. Compared to the total sample and other clusters, the proportions of males 
and females differed only in the "Eating disordered behaviors" cluster (for other clusters, Fisher's exact test, $p<0.05)$.

\subsection{Analysis of variance}

Using one-way analysis of variance and Tukey's HSD posthoc tests (shown in Table 2), we compared the four clusters based on MBSRQ subscale scores, age, educational level and BMI.

In comparison with all other clusters, the "Orthorexic behaviors" cluster displayed greater scores in health orientation, fitness evaluation and fitness orientation. Regarding health evaluation, the "Orthorexic behaviors " and "Low" clusters showed higher scores compared with the "Eating disordered behaviors" or "Obsessive-compulsive behaviors" clusters. Illness orientation differed only between the "Low" and "Orthorexic behaviors" or "Eating disordered behaviors" clusters.

In comparison with all other clusters, the "Eating disordered behaviors" cluster displayed greater scores in self-classified weight, overweight preoccupation and appearance orientation but lower scores in appearance evaluation and body areas satisfaction. In addition, compared with the "Low" cluster, the "Orthorexic behaviors" cluster showed greater scores in appearance orientation and overweight preoccupation, but no significant difference between these clusters was observed neither in self-classified weight, nor in appearance evaluation or body areas satisfaction.

The "Eating disordered behaviors" cluster had the highest BMI level among all other clusters and the "Orthorexic behaviors" cluster had higher level of BMI compared with the "Low" cluster. In addition, the "Orthorexic behaviors" cluster had higher educational level and older age then the "Eating disordered behaviors" and "Obsessive-compulsive behaviors" clusters, but no significant difference was found between the "Orthorexic behaviors " and "Low" clusters regarding these variables. However, the effect sizes for these differences were found to be very small $\left(\eta^{2}\right.$ ranged between .01 and .05).

\section{Discussion}

To our knowledge, this is the first study to explore the typology of young adults from a large non-clinical sample based on orthorexic, eating disordered and obsessive-compulsive behaviors. This study also represents a first attempt to compare individuals' attitudes towards body image depending on their ON, ED and OCD behaviors. 
Cluster analysis based on ON, ED and OCD behaviors was used to identify a typology of young adults. A hierarchical cluster analysis extracted a four-cluster solution characterized by the following groups: an "Orthorexic behaviors" group that was one SD above the mean on EHQ score, a "Eating disordered behaviors" group that was one and half SD above the mean on EDI-3, an "Obsessive-compulsive behaviors" group that was one and half SD above the mean on OCI-R, and a "Low" group that was below the mean by more than half a SD value on all behaviors. The "Eating disordered behaviors" group and the "Obsessive-compulsive behaviors" group could be considered to represent subclinical ED and OCD which both have been defined by scores greater than or equal to one SD value above the mean $[44,45]$. Similarly, the "Orthorexic behaviors" group was one SD above the mean on EHQ score. In addition, the mean EHQ score of the "orthorexic behaviors" cluster (48.54) was significantly higher than the mean EHQ score found in the original study sample (39.05) [34] (with Cohen's $d=.89$, indicating a large effect size).

Although several differences displayed small effect size, results show that all clusters differed from each others on virtually all variables. First, the "Orthorexic behaviors" cluster showed greater association with health orientation, fitness evaluation and orientation compared with all other clusters. This association of ON with implication in healthy lifestyle and regular physical activity have been described previously $[17,23]$.

Furthermore, in comparison to other clusters, the "Eating disordered behaviors" cluster displayed greater scores in appearance orientation, overweight preoccupation, self-classified weight and lower scores in body satisfaction. Since body image disturbance and dissatisfaction are wellknown 201 these results were expected. Similarly, the "Orthorexic behaviors" cluster, in comparison with the "Low" cluster, displayed greater scores in appearance orientation and overweight preoccupation. This is in line with previous studies that found a positive correlation between orthorexic behaviors, appearance orientation and overweight preoccupation [22, 23]. However, we found no significant differences between these clusters regarding self-classified weight or body satisfaction, which may contrast with previous research that reported a positive correlation between orthorexic behaviors and these variables [22, 23]. This discrepancy might be related to usage of different measures of ON in mentioned studies $[22,23]$ and in the current study. 
In the first sight, our results showing that both "Orthorexic behaviors" and "Eating disordered behaviors" clusters displayed greater appearance orientation and overweight preoccupation compared to the "Low" cluster, could be interpreted as an important resemblance between ON and ED. However, while the "Eating disordered behaviors" cluster was characterized with highest selfclassified weight and body dissatisfaction, no significant difference between "Orthorexic behaviors" and "Low" clusters was observed in these subscales. This is in line with previous research suggesting no significant relationship between orthorexic behaviors and body dissatisfaction [25] or weight and shape-related concerns $[1,19]$. Thus, we can argue that, contrary to "Eating disordered behaviors" cluster, "Orthorexic behaviors" cluster's appearance orientation and overweight preoccupation might rather be explained by fitness and health related concerns than body image disturbance or dissatisfaction.

As we know, this is the first time that $\mathrm{ON}$ and subclinical OCD were compared regarding their body image attitudes. As mentioned earlier, we found several differences between the "Orthorexic behaviors" and "Obsessive-compulsive behaviors" clusters in health and fitness related subscales. This implies that subclinical levels of ON and OCD could differ regarding some important aspects of body image attitudes. Moreover, we found no significant differences between the "Orthorexic behaviors" and "Low" clusters regarding presence of OCD behaviors. This is in accordance with a study [21] which also found no significant relationship between OCD behaviors and orthorexic behaviors. This further supports the idea that OCD behaviors did not play a significant role in ON. However, we should note that the OCI-R assesses ego-dystonic obsessive-compulsive behaviors (i.e., thoughts and behaviors that are in conflict with one's values and self-image).

Therefore future studies should investigate if ego-syntonic obsessive-compulsive behaviors could play a role in $\mathrm{ON}$.

Moreover, only the "Eating disordered behaviors" cluster displayed significant differences in the proportions of males and females $(p>0.05)$. This result was not unexpected since eating disorders are known to be more common in women than men [31]. However, we found no significant difference on the EHQ score between males and females. This is consistent with previous studies [7, 8, 21] which also did not find any sex-related differences in orthorexic behaviors. Nonetheless, a majority 
$(84.6 \%)$ of the participants in the current study were women, therefore, this result should be treated with caution.

Moreover, the "Orthorexic behaviors" cluster reported higher levels of BMI compared to "Low" Cluster. Although this finding is in contrast with some recent studies [46] it is consistent with findings on positive correlation between $\mathrm{ON}$ and $\mathrm{BMI}[8,10]$. However, as the effect sizes for these comparisons were found to be small, we cannot rule out the possibility that these results are due to our overpowered sample. In addition, we found no significant difference between the "Orthorexic behaviors" and "Low" clusters regarding age or educational level. These findings are in line with previous research who also found no educational level [7] or age-related differences [9] between individuals with and without orthorexic behaviors.

Further, several limitations to this study need to be acknowledged. Firstly, this study was conducted with a non-clinical sample and was restricted to the young adult age range. Thus, findings from this study cannot be generalizable to different age groups or to clinical populations. Secondly, we used an online recruitment strategy which restricted our sample to only people who have access to social media. This issue further limited the generalizability of findings to general population. Thirdly, the study was exploratory (rather than hypothesis or theory-driven), descriptive and cross-sectional, and thus it cannot explain the causal interactions between findings or whether the identified profiles are stable over time or whether individuals may switch from one group to the other. Longitudinal studies are needed to analyze these issues. Because of the limitations listed above, we cannot rule out the possibility that our clusters may reflect the choices made in terms of the sampling and assessment in the current study. Future studies should consider employing typological approach and the use of cluster analysis to assess ON behaviors and its differences from other disorders, in clinical or adult populations where levels of ON, ED and OCD behaviors are relatively higher compared to those of non-clinical student populations.

It is also important to note that the use of EDI-3 Bulimia and Drive for Thinness subscales does not fully assess eating disordered behaviors and does not allow the diagnosis of eating disorders. Finally, several authors suggested that the EHQ ignored the negative emotionality [47] that can be associated with the overwhelming concern about eating unhealthy foods. Valid and reliable 
measurement tools considering these aspects are needed to overcome our lack of understanding of ON construct.

It is also important to note that in the current study, the translation and back-translation were conducted by the authors who were bilingual and well-knowledgeable about both original and target cultures. Yet, the use of professional translators with relevant expertise for the translation and cultural adaptation processes can be preferred in order to point out other potential linguistic, psychological, and cultural differences between American and French populations. Additionally, a backward translation design was used to maximize the suitability of the test adaptation while translating the EHQ into French language. However, future studies should consider a double-translation and reconciliation procedure as it seems more powerful in detecting discrepancies, minimizing the impact of cultural differences and thus maximizing the suitability of the test adaptation [48]. Future studies should also consider collecting qualitative evidence in order to predict any cultural or linguistic differences before adapting a test to another language [48].

\section{Conclusion}

Despite these limitations, to our knowledge this study is the first to identify the typology of young adults from a large non-clinical sample based on ON, ED and OCD behaviors. Our findings provide evidence for the existence of a distinct group of individuals with orthorexic behaviors characterized with positive body image attitudes compared to subclinical ED and OCD. Our results also document pending questions about sex, age, educational level and BMI-related differences between the "Orthorexic behaviors", "Eating disordered behaviors" and "Obsessive-compulsive behaviors" clusters. Together, findings from this study offer support for the possibility of ON being a distinct condition from ED and OCD. While reporting no conclusive answer to the question of whether $\mathrm{ON}$ is a totally pathological entity or not, our results may be useful to future studies for deepening our understanding of $\mathrm{ON}$, for establishing eventually a diagnostic criteria or preventive measures. 


\section{Declarations}

Acknowledgments: We would like to thank Pr. David H. Gleaves for giving us the permission to translate the Eating Habits Questionnaire.

\section{Funding}

No funding was provided for this study.

\section{Conflicts of interest}

The authors have no conflicts of interest to declare.

\section{Ethics approval}

The study protocol was approved by the local ethics committee (Comité d'Éthique de la Recherche of Toulouse University).

\section{Consent to participate}

All participants agreed to give their free and informed consent prior to completing the study.

\section{Consent for publication}

All participants were informed that the results from this study were going to be published in scientific journals or congress.

\section{Availability of data and material}

The authors do not have permission to share data.

\section{Code availability}

Not applicable.

\section{Authors' contributions}

EY and HC designed the study and wrote the protocol. EY conducted literature searches, provided summaries of previous research studies and conducted the statistical analysis. All authors participated in the translation and back-translation processes of the questionnaires. EY wrote the first draft of the manuscript, HC and PR supervised the writing process. All authors contributed to and have approved the final manuscript. 


\section{References}

[1] Dunn TM, Bratman S (2016). On orthorexia nervosa: A review of the literature and proposed diagnostic criteria. Eat Behav. 21:11-17. https://doi.org/10.1016/j.eatbeh.2015.12.006

[2] Barthels F, Meyer F, Pietrowsky R (2015). Orthorexic eating behavior. A new type of disordered eating. Ernahrungs Umsch 62(10):156-161. https://doi.org/10.4455/eu.2015.029

[3] Moroze RM, Dunn TM, Craig Holland J, Yager J, Weintraub P (2015). Microthinking About Micronutrients: A Case of Transition From Obsessions About Healthy Eating to Near-Fatal “Orthorexia Nervosa" and Proposed Diagnostic Criteria. Psychosomatics 56(4):397-403. https://doi.org/10.1016/j.psym.2014.03.003

[4] Park SW, Kim JY, Go GJ, Jeon ES, Pyo HJ, Kwon YJ (2011). Orthorexia Nervosa with Hyponatremia, Subcutaneous Emphysema, Pneumomediastimum, Pneumothorax, and Pancytopenia. Electrolytes Blood Press 9(1):32. https://doi.org/10.5049/EBP.2011.9.1.32

[5] Dunn TM, Gibbs J, Whitney N, Starosta A (2017). Prevalence of orthorexia nervosa is less than $1 \%$ : data from a US sample. Eat Weight Disord - Stud Anorex Bulim Obes 22(1):185-192. https://doi.org/10.1007/s40519-016-0258-8

[6] Ramacciotti CE, Perrone P, Coli E, et al (2011). Orthorexia nervosa in the general population: A preliminary screening using a self-administered questionnaire (ORTO-15). Eat Weight Disord - Stud Anorex Bulim Obes 16(2):e127-e130. https://doi.org/10.1007/BF03325318

[7] Aksoydan E, Camci N (2009). Prevalence of orthorexia nervosa among Turkish performance artists. Eat Weight Disord 14(1): 33-37. https://doi.org/10.1007/BF03327792

[8] Fidan T, Ertekin V, Işikay S, Kırpınar I (2010). Prevalence of orthorexia among medical students in Erzurum, Turkey. Compr Psychiatry 51(1):49-54. https://doi.org/10.1016/j.comppsych.2009.03.001

[9] Herranz Valera J, Acuña Ruiz P, Romero Valdespino B, Visioli F (2014). Prevalence of orthorexia nervosa among ashtanga yoga practitioners: a pilot study. Eat Weight Disord Stud Anorex Bulim Obes 19(4):469-472. https://doi.org/10.1007/s40519-014-0131-6 
[10] Oberle CD, Samaghabadi RO, Hughes EM (2017). Orthorexia nervosa: Assessment and correlates with gender, BMI, and personality. Appetite 108:303-310. https://doi.org/10.1016/j.appet.2016.10.021

[11]. Varga M, Dukay-Szabó S, Túry F, van Furth Eric F (2013). Evidence and gaps in the literature on orthorexia nervosa. Eat Weight Disord - Stud Anorex Bulim Obes 18(2):103-111. https://doi.org/10.1007/s40519-013-0026-y

[12] Valente M, Syurina EV, Donini LM (2019). Shedding light upon various tools to assess orthorexia nervosa: a critical literature review with a systematic search. Eat Weight Disord Stud Anorex Bulim Obes 24(4):671-682. https://doi.org/10.1007/s40519-019-00735-3

[13] Depa J, Schweizer J, Bekers S-K, Hilzendegen C, Stroebele-Benschop N (2017). Prevalence and predictors of orthorexia nervosa among German students using the 21-item-DOS. Eat Weight Disord - Stud Anorex Bulim Obes 22(1):193-199. https://doi.org/10.1007/s40519-016-0334-0

[14] Heiss S, Coffino JA, Hormes JM (2019). What does the ORTO-15 measure? Assessing the construct validity of a common orthorexia nervosa questionnaire in a meat avoiding sample. Appetite 135:93-99. https://doi.org/10.1016/j.appet.2018.12.042

[15] American Psychiatric Association (2013). Diagnostic and statistical manual of mental disorders (5th ed.). Washington, DC: American Psychiatric Publishing.

[16] World Health Organization (2018). International statistical classification of diseases and related healthproblems (11th Revision).

[17] Killen JD, Taylor CB, Hayward C, Haydel KF, Wilson DM, Hammer L, et al (1996). Weight concerns influence the development of eating disorders: A 4-year prospective study. J Consult Clin Psychol, 64(5) : 936-940. http://dx.doi.org/10.1037/0022-006X.64.5.936

[18] Stice E, Marti CN, Durant S (2011). Risk factors for onset of eating disorders: Evidence of multiple risk pathways from an 8-year prospective study. Behav Res Ther, 49(10): 622-627. https://doi.org/10.1016/j.brat.2011.06.009

[19] Bratman S, Knight D (2000). Health food junkies: Orthorexia nervosa: Overcoming the obsession with healthful eating. Broadway, New York. 
[20] Segura-García C, Papaianni MC, Caglioti F, et al (2012). Orthorexia nervosa: A frequent eating disordered behavior in athletes. Eat Weight Disord - Stud Anorex Bulim Obes 17(4). https://doi.org/10.3275/8272

[21] Mcinerney-Ernst EM (2012). Orthorexia nervosa: Real construct or newest social trend? Doctoraldissertation, University of Missouri-Kansas City

[22] Barnes MA, Caltabiano ML (2017). The interrelationship between orthorexia nervosa, perfectionism, body image and attachment style. Eat Weight Disord - Stud Anorex Bulim Obes 22(1):177-184. https://doi.org/10.1007/s40519-016-0280-x

[23] Brytek-Matera A, Donini LM, Krupa M, Poggiogalle E, Hay P (2016). Erratum to: Orthorexia nervosa and self-attitudinal aspects of body image in female and male university students. $\mathbf{J}$ Eat Disord 4(1):16. https://doi.org/10.1186/s40337-016-0105-3

[24] Barthels, F., Kisser, J. \& Pietrowsky, R (2020). Orthorexic eating behavior and body dissatisfaction in a sample of young females. Eat Weight Disord. https://doi.org/10.1007/s40519-020-00986-5

[25] Segura-Garcia C, Ramacciotti C, Rania M, et al (2015). The prevalence of orthorexia nervosa among eating disorder patients after treatment. Eat Weight Disord - Stud Anorex Bulim Obes 20(2):161-166. https://doi.org/10.1007/s40519-014-0171-y

[26] Barthels F, Meyer F, Huber T, Pietrowsky R (2017). Orthorexic eating behaviour as a coping strategy in patients with anorexia nervosa. Eat Weight Disord - Stud Anorex Bulim Obes 22(2):269-276. https://doi.org/10.1007/s40519-016-0329-x

[27] Mathieu J (2005). What Is Orthorexia? J Am Diet Assoc 105(10):1510-1512. https://doi.org/10.1016/j.jada.2005.08.021

[28] Koven N, Abry A (2015). The clinical basis of orthorexia nervosa: emerging perspectives. Neuropsychiatr Dis Treat. 11: 385-394. https://doi.org/10.2147/NDT.S61665

[29] Vogt W, Nagel D (1992). Cluster Analysis in Diagnosis. Clin Chem 38(2):182-198. https://doi.org/10.1093/clinchem/38.2.182 
[30] Gibbs NA (1996). Nonclinical populations in research on obsessive-compulsive disorder: A critical review. Clin Psychol Rev 16(8):729-773. https://doi.org/10.1016/S02727358(96)00043-8

[31] Neumark-Sztainer D, Hannan PJ (2000). Weight-Related Behaviors Among Adolescent Girls and Boys: Results From a National Survey. Arch Pediatr Adolesc Med 154(6):569. https://doi.org/10.1001/archpedi.154.6.569

[32] Sun X, So SH, Chiu C-D, Chan RC, Leung PW (2018). Paranoia and anxiety: A cluster analysis in a non-clinical sample and the relationship with worry processes. Schizophr Res 197:144149. https://doi.org/10.1016/j.schres.2018.01.024

[33] Laredo-Aguilera JA, Cobo-Cuenca AI, Santacruz-Salas E, et al (2019). Levels of Physical Activity, Obesity and Related Factors in Young Adults Aged 18-30 during 2009-2017. Int J Environ Res Public Health. 16(20):4033. https://doi.org/10.3390/ijerph16204033

[34] Gleaves DH, Graham EC, Ambwani S (2013). Measuring 'orthorexia': Development of the Eating Habits Questionnaire. Int J Educ Psychol Assess,12(2) :1-18.

[35] Turgeon M-ÈK, Meilleur D, Blondin S (2015). Évaluation des attitudes et des comportements alimentaires : comparaison entre un groupe d'adolescentes athlètes pratiquant un sport esthétique et un groupe témoin. Neuropsychiatr Enfance Adolesc 63(3):175-182. https://doi.org/10.1016/j.neurenf.2015.01.001

[36] Fernandez S, Pritchard M (2012). Relationships between self-esteem, media influence and drive for thinness. Eat Behav 13(4):321-325. https://doi.org/10.1016/j.eatbeh.2012.05.004

[37] Magurean S, Sălăgean N, Tulbure BT (2016). Factor structure and Psychometric properties of two short versions of Frost Multidimensional Perfectionism Scale in Romania. Rom J Exp Appl Psychol. 6, 53. https://doi.org/10.15303/rjeap.2016.si1.a43

[38] Zermatten A, Van der Linden M, Jermann F, Ceschi G (2006). Validation of a French version of the Obsessive-Compulsive Inventory-Revised in a non-clinical sample. Eur Rev Appl Psychol 56(3):151-155. https://doi.org/10.1016/j.erap.2005.07.003

[39] Cash, T. F. (2000). The Multidimensional Body-Self Relations Questionnaire. (Third Revision). 
[40] Untas A, Koleck M, Rascle N, Borteyrou X (2009). Psychometric Properties of the French Adaptation of the Multidimensional Body Self Relations Questionnaire-Appearance Scales. Psychol Rep 105(2):461-471. https://doi.org/10.2466/PR0.105.2.461-471

[41] Tabachnick BG, Fidell LS (2001) Using Multivariate Statistics. (4th Ed.), Allyn and Bacon, Boston.

[42] Mulaik SA, James LR, Alstine JV, Bennett N, Lind S, Stilwell CD (1989). Evaluation of goodness-of-fit indices for structural equation models. Psychol Bull, 105(3),430-445.

[43] Hu L, Bentler PM (1999). Cutoff criteria for fit indexes in covariance structure analysis: Conventional criteria versus new alternatives. Struct Equ Model Multidiscip J 6(1):1-55. https://doi.org/10.1080/10705519909540118

[44] Hammerle F, Huss M, Ernst V, Bürger A (2016). Thinking dimensional: prevalence of DSM-5 early adolescent full syndrome, partial and subthreshold eating disorders in a cross-sectional survey in German schools. BMJ Open 6(5):e010843. https://doi.org/10.1136/bmjopen-2015010843

[45] Mataix-Cols D, Vallejo J, Sànchez-Turet M (2000). The cut-off point in sub-clinical obsessivecompulsive research. Behav Cogn Psychother 28(3):225-233. https://doi.org/10.1017/S1352465800003039

[46] Oberle CD, Lipschuetz SL (2018). Orthorexia symptoms correlate with perceived muscularity and body fat, not BMI. Eat Weight Disord - Stud Anorex Bulim Obes 23(3):363-368. https://doi.org/10.1007/s40519-018-0508-z

[47] Roncero M, Barrada JR, Perpiñá C (2017). Measuring Orthorexia Nervosa: Psychometric Limitations of the ORTO-15. Span J Psychol 20: E41. https://doi.org/10.1017/sjp.2017.36

[48] Bartram D, Hambleton RK, Grégoire J, Muñiz J et al (2017). ITC Guidelines for Translating and Adapting Tests (Second Edition), Int J Test, https://doi.org/10.1080/15305058.2017.1398166 
Table 1

Descriptive statistics and reliabilities for all variables

\begin{tabular}{lcccc}
\hline & Sample & & & \\
& $\mathrm{N}=921$ & Range & $\alpha$ & $M I C$ \\
& $\mathrm{M}(\mathrm{SD})$ & & & \\
\hline ON behaviors & $39.53(10.05)$ & $21-81$ & .89 & .29 \\
ED behaviors & $34.85(13.28)$ & $14-82$ & .88 & .37 \\
OCD behaviors & $18.31(11.56)$ & $0-65$ & .87 & .28 \\
Health Orientation & $3.04(.66)$ & $1-5$ & .69 & .21 \\
Health Evaluation & $3.48(.74)$ & $1-5$ & .62 & .24 \\
Illness Orientation & $2.9(.88)$ & $1-5$ & .75 & .38 \\
Fitness Orientation & $2.92(.87)$ & $1-5$ & .90 & .41 \\
Fitness Evaluation & $2.96(.93)$ & $1-5$ & .64 & .37 \\
Self-Classified Weight & $3.16(.66)$ & $1-5$ & .82 & .70 \\
Overweight Preoccupation & $2.2(.89)$ & $1-5$ & .69 & .36 \\
Appearance Orientation & $3.15(.73)$ & $1-5$ & .85 & .34 \\
Appearance Evaluation & $3.1(.87)$ & $1-5$ & .87 & .50 \\
Body Areas Satisfaction & $3.2(.69)$ & $1-5$ & .79 & .31 \\
BMI & $21.96(3.96)$ & $16-61.28$ & n.a & n.a \\
Educational level & $2.92(1.27)$ & $1-7$ & n.a & n.a \\
Age & $20.72(2.63)$ & $18-30$ & n.a & n.a
\end{tabular}

Note. $\alpha=$ Cronbach's alpha. MIC = mean interitem correlation; $n . a=$ not applicable. ON, ED and OCD behaviors were measured using the Eating Habits Questionnaire, the Eating Disorders Inventory-3 and the Obsessive-compulsive Inventory-Revised, respectively. 
Table 2

Cluster analysis based on Orthorexic, Eating disordered and Obsessive-compulsive behaviors. Cluster comparison using ANOVA and post-hoc tests.

\begin{tabular}{|c|c|c|c|c|c|c|c|}
\hline & \multicolumn{4}{|c|}{ Cluster $M(S D)$} & \multirow{3}{*}{$F$} & \multirow{3}{*}{$\eta^{2}$} & \multirow{3}{*}{$\begin{array}{l}\text { Significant } \\
\text { comparisons }\end{array}$} \\
\hline & $\begin{array}{c}\text { obsessive- } \\
\text { compulsive } \\
\text { behaviors }\end{array}$ & low & $\begin{array}{l}\text { orthorexic } \\
\text { behaviors }\end{array}$ & $\begin{array}{c}\text { eating } \\
\text { disordered } \\
\text { behaviors }\end{array}$ & & & \\
\hline & $n=131(14 \%)$ & $n=394(42 \%)$ & $n=241(26 \%)$ & $n=155(16 \%)$ & & & \\
\hline ON behaviors & $41.47(9.27)$ & $31.7(4.94)$ & $48.54(6.5)$ & $43.67(9.77)$ & $313.54 *$ & .50 & $\mathrm{O}>\mathrm{ED}>\mathrm{OC}>\mathrm{L}$ \\
\hline ED behaviors & $35.74(9.78)$ & $28.13(7.71)$ & $30.91(7.84)$ & $57.32(8.7)$ & $490.28 *$ & .61 & $\mathrm{ED}>\mathrm{OC}>\mathrm{O}>\mathrm{L}$ \\
\hline OCD behaviors & $37.8(7.3)$ & $12.86(7.02)$ & $13.97(6.69)$ & $22.28(10)$ & $391.56^{*}$ & .56 & $\mathrm{OC}>\mathrm{ED}>\mathrm{O}, \mathrm{L}$ \\
\hline Heath Orientation & $3.08(.67)$ & $2.75(.59)$ & $3.5(.52)$ & $3.03(.61)$ & $78.66^{*}$ & .20 & $\mathrm{O}>\mathrm{ED}, \mathrm{OC}>\mathrm{L}$ \\
\hline Health Evaluation & $3.17(.75)$ & $3.58(.68)$ & $3.72(.68)$ & $3.08(.74)$ & $36.96^{*}$ & .11 & $\mathrm{O}, \mathrm{L}>\mathrm{OC}, \mathrm{ED}$ \\
\hline Illness Orientation & $2.96(.95)$ & $2.77(.84)$ & $3.02(.84)$ & $3.01(.96)$ & $5.11 *$ & .01 & $\mathrm{O}, \mathrm{ED}>\mathrm{L}$ \\
\hline Fitness Orientation & $2.87(.91)$ & $2.73(.85)$ & $3.28(.83)$ & $2.86(.77)$ & $21.74 *$ & .06 & $\mathrm{O}>\mathrm{ED}, \mathrm{OC}, \mathrm{L}$ \\
\hline Fitness Evaluation & $2.77(.94)$ & $2.98(.92)$ & $3.2(.87)$ & $2.72(.95)$ & $10.96^{*}$ & .03 & $\mathrm{O}>\mathrm{ED}, \mathrm{OC}, \mathrm{L} \mathrm{L}>\mathrm{ED}$ \\
\hline
\end{tabular}




\begin{tabular}{|c|c|c|c|c|c|c|c|}
\hline & \multicolumn{4}{|c|}{ Cluster $M(S D)$} & \multirow{3}{*}{$F$} & \multirow{3}{*}{$\eta^{2}$} & \multirow{3}{*}{$\begin{array}{l}\text { Significant } \\
\text { comparisons }\end{array}$} \\
\hline & $\begin{array}{c}\text { obsessive- } \\
\text { compulsive } \\
\text { behaviors }\end{array}$ & low & $\begin{array}{l}\text { orthorexic } \\
\text { behaviors }\end{array}$ & $\begin{array}{c}\text { eating } \\
\text { disordered } \\
\text { behaviors }\end{array}$ & & & \\
\hline & $n=131(14 \%)$ & $n=394(42 \%)$ & $n=241(26 \%)$ & $n=155(16 \%)$ & & & \\
\hline Self-Classified Weight & $2.97(.66)$ & $3.02(.61)$ & $3.14(.57)$ & $3.69(.64)$ & $49.38 *$ & .13 & $\mathrm{ED}>\mathrm{O}, \mathrm{OC}, \mathrm{L}$ \\
\hline Overweight Preoccupation & $2.18(.79)$ & $1.73(.58)$ & $2.29(.86)$ & $3.28(.7)$ & $174.36^{*}$ & .36 & $\mathrm{ED}>\mathrm{OC}, \mathrm{O}>\mathrm{L}$ \\
\hline Appearance Orientation & $3.28(.68)$ & $2.98(.7)$ & $3.16(.7)$ & $3.47(.74)$ & $18.91 *$ & .36 & $\mathrm{ED}>\mathrm{O}>\mathrm{L} \quad \mathrm{OC}>\mathrm{L}$ \\
\hline Appearance Evaluation & $3.12(.86)$ & $3.23(.79)$ & $3.37(.77)$ & $2.4(.85)$ & $50.53 *$ & .14 & $\mathrm{O}, \mathrm{L}, \mathrm{OC}>\mathrm{ED} \mathrm{O}>\mathrm{OC}$ \\
\hline Body Areas Satisfaction & $3.17(.6)$ & $3.32(.64)$ & $3.42(.66)$ & $2.2(.59)$ & $55.98 *$ & .15 & $\mathrm{O}, \mathrm{L}, \mathrm{OC}>\mathrm{ED} \mathrm{O}>\mathrm{OC}$ \\
\hline BMI & $21.19(4.23)$ & $21.36(3.46)$ & $22.19(4.17)$ & $23.8(4.01)$ & $16.71 *$ & .05 & $\mathrm{ED}>\mathrm{O}, \mathrm{OC}, \mathrm{L} \quad \mathrm{O}>\mathrm{L}$ \\
\hline Educational level & $2.63(1.05)$ & $2.99(1.28)$ & $3.08(1.37)$ & $2.72(1.19)$ & $5.18 *$ & .01 & $\mathrm{O}>\mathrm{ED}, \mathrm{OC} \quad \mathrm{L}>\mathrm{OC}$ \\
\hline Age & $19.98(2.09)$ & $20.83(2.58)$ & $21.23(2.87)$ & $20.27(2.58)$ & $8.34 *$ & .02 & $\mathrm{O}>\mathrm{OC}, \mathrm{ED} \quad \mathrm{L}>\mathrm{OC}$ \\
\hline
\end{tabular}

Note. ON, ED and OCD behaviors were measured using the Eating Habits Questionnaire, the Eating Disorders Inventory-3 and the Obsessive-compulsive Inventory-Revised, respectively. $d f$ (residual) $=917$ and $d f$ (clusters) $=3$ for all comparisons.

$* p=\leq 001$ 
Fig.1 K-means clustering: Graph of means for four cluster solution based on ON, ED and OCD behavior

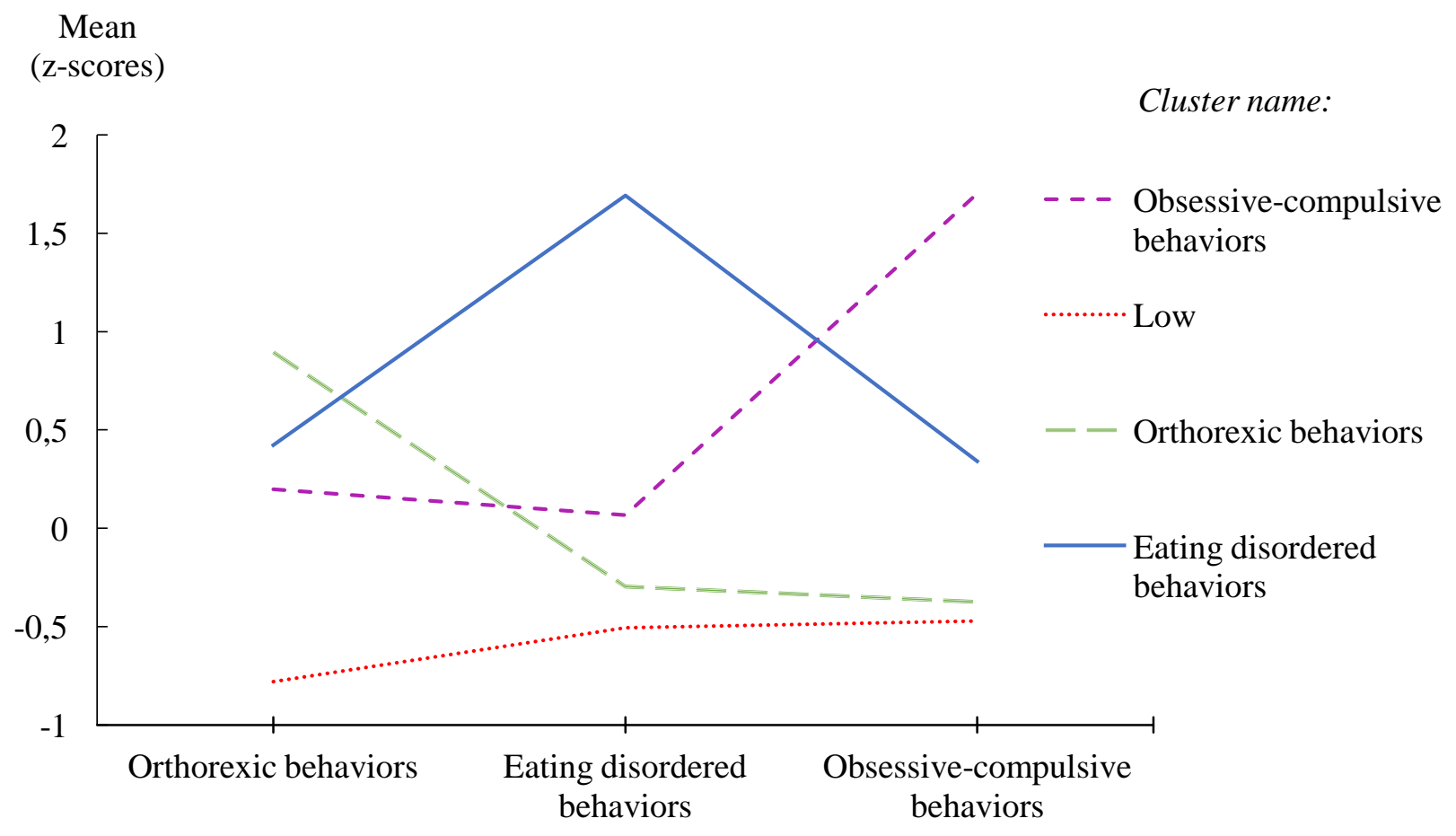


ORTHOREXIA NERVOSA, A DISTINCT CONDITION? 
ORTHOREXIA NERVOSA, A DISTINCT CONDITION? 